Provided for non-commercial research and education use. Not for reproduction, distribution or commercial use.

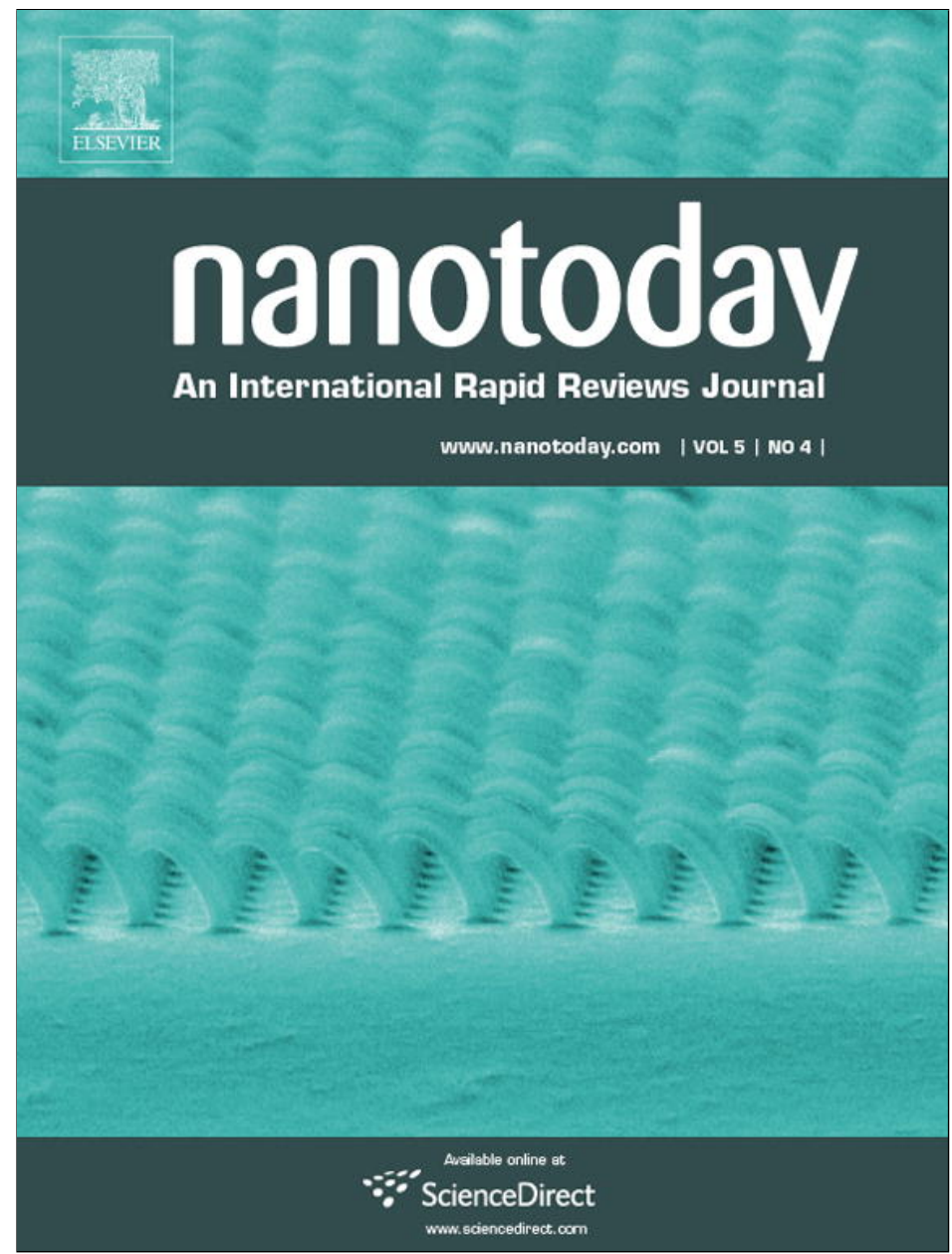

This article appeared in a journal published by Elsevier. The attached copy is furnished to the author for internal non-commercial research and education use, including for instruction at the authors institution and sharing with colleagues.

Other uses, including reproduction and distribution, or selling or licensing copies, or posting to personal, institutional or third party websites are prohibited.

In most cases authors are permitted to post their version of the article (e.g. in Word or Tex form) to their personal website or institutional repository. Authors requiring further information regarding Elsevier's archiving and manuscript policies are encouraged to visit:

http://www.elsevier.com/copyright 


\title{
Just scratching the surface? New techniques show how surface functionality of nanoparticles influences their environmental fate
}

\author{
Helen P. Jarvie ${ }^{a, *}$, Stephen M. King ${ }^{b}$ \\ a Centre for Ecology \& Hydrology, Maclean Building, Benson Lane, Crowmarsh Gifford, \\ Wallingford OX10 8BB, UK \\ b STFC ISIS Facility, Rutherford Appleton Laboratory, Harwell Science and Innovation Campus, \\ Didcot OX11 OQX, UK
}

Received 15 March 2010; received in revised form 28 May 2010; accepted 9 June 2010 Available online 8 July 2010

\author{
KEYWORDS \\ Nanoparticle; \\ Environmental fate; \\ Surface \\ functionalisation; \\ Coating; \\ Wastewater; \\ River; \\ Small-angle neutron \\ scattering (SANS)
}

\begin{abstract}
This Opinion Article highlights how new applications of techniques such as neutron scattering are offering greater insights into the processes, mechanisms and rates controlling the behaviour and fate of nanoparticles in different environmental compartments. Such information is vital for successful predictive modelling of the environmental fate of engineered nanoparticles in the post-production stages of their lifecycles. The role of surface functionality (surface coatings) in influencing environmental pathways of nanoparticles is specifically discussed.

(c) 2010 Elsevier Ltd. All rights reserved.
\end{abstract}

The 'nanotechnology revolution' offers the prospect of vast benefits to society, through applications of nanomaterials in medicine, new energy technologies and environmental remediation, along with the development of a prodigious variety of consumer products. Currently, though, there are major strategic knowledge gaps concerning the post-production life cycles of even the most widely used nanoparticles, from their entry into the environment as

\footnotetext{
* Corresponding author. Tel.: +44 1491838800.

E-mail address: hpj@ceh.ac.uk (H.P. Jarvie).
}

'used product', their environmental pathways, to their final environmental fates and potential ecotoxicological effects [1].

One of the main difficulties for scientists investigating the environmental pathways and fate of nanoparticles has been simply detecting and quantifying them in statistically significant numbers in complex environmental matrices such as sewage and river water [2]. Routine analytical chemistry methods struggle to differentiate between background chemical forms and the nanoparticle phases. Light scattering is hampered by background turbidity. Electron and atomic force microscopy can image nanoparticles, but rely 
on counting individual particles and cannot track behaviour in natural aqueous matrices in real time. Indeed, it is the colloidal behaviour of engineered nanoparticles (i.e. whether they aggregate together, or with natural colloidal material, and then sediment out or remain dispersed within the aqueous phase in different environmental compartments), which plays such a critical role in determining their environmental pathways and routes of ecological exposure [2].

One of the recent steps forward in studying how nanoparticles behave and are transported in aquatic environments, is the use of small-angle scattering methods, particularly with neutrons [3,4]. Neutrons easily penetrate sewage and river water but scatter strongly from the nanoparticles, allowing measurement of concentration, size, shape and aggregation. A neutron scattering technique called 'contrast variation' also makes it possible to selectively suppress scattering from different components and directly investigate the interactions of inorganic and organic nanophases. We have recently used small-angle neutron scattering [4], to show how coating or 'functionalising' the surface of silica nanoparticles with a thin adsorbed layer of a commonly used non-ionic surfactant dramatically alters their fate within wastewater treatment. Silica nanoparticles are part of a wider class of engineered oxide nanoparticles (commonly used in household cleaners, personal care products and pharmaceutical formations). In many of these commercial products, surfactant and/or polymer will also be present as detergents or viscosity modifiers and, indeed, may be designed to physically adsorb onto the surface of the nanoparticles to promote their dispersion within the formulation. Our results showed a dramatic difference between the behaviour of coated and uncoated particles in wastewater. The surfactantcoated nanoparticles rapidly aggregated and sedimentated out to form part of the solid sewage sludge. Aggregation resulted from interactions between the adsorbed surfactant molecules and organic matter in the sewage. Conversely, uncoated nanoparticles remained dispersed in the sewage and therefore simply continue through the effluent stream.

To complicate matters even further, some nanoparticles will lose, change or gain new coatings, including natural organic matter, during their transit through aquatic environments [5]. Indeed, microbial action may play an important role in modifying nanoparticle surface coatings. Surface functionalisation of nanoparticles with varying concentrations of natural organic matter in river water has been found to result in dramatic shifts between aggregation and stabilisation of nanoparticles $[6,7]$. In rivers, aggregation and sedimentation of nanoparticles results in their storage in river-bed sediments, which slows their downstream transport, but means greater exposure to nanoparticles for organisms which live on, or in, the river bed.

All this points to the importance of nanoparticle surface chemistry in controlling environmental pathways and fate. Preliminary indications are that, by modifying the surface functionalisation of nanoparticles, it might be possible to influence their environmental pathways and ecologi- cal exposure routes. For example, in the case of primary wastewater treatment, changes in the surface coatings of nanoparticles might be exploited to bring about a shift from an effluent (aquatic) pathway, to a terrestrial pathway, via sludge disposal to land. However, simply changing the pathway of the nanomaterials into the environment does not mitigate ecotoxicological risk, it simply changes the target [5]. The widespread use of sewage sludge as an agricultural fertiliser raises important issues of interactions with soil biota and potential for uptake by plants and crops. Moreover, nanoparticles applied to the land in sewage sludge may ultimately be transported into surface water bodies via 'diffuse' or 'non-point' pathways, mobilised by runoff during rainfall events, or leach into groundwater. However, within each environmental compartment that a nanoparticle moves through, it will be subject to a whole host of interactions with the surrounding aqueous and solid phases and biota. These processes may promote or retard nanoparticle transport or translocation through each environmental compartment and are primarily mediated by surface chemical interactions.

Large-scale neutron and synchrotron X-ray facilities offer the environmental science community considerable opportunities for both detailed and time-resolved studies of nanoparticle behaviour and interactions in real environmental matrices, such as wastewaters, surface and ground waters, soils and sediments. These studies are starting to provide new insights into the processes, mechanisms and rates controlling the behaviour of engineered nanoparticles in different environmental compartments. Crucially, this is highlighting the importance of understanding the relationships between surface functionality of nanoparticles and how they behave in the natural environment and their ultimate destinations. These sorts of studies, along with developments in controlled in situ nanoparticle tracing in the natural environment, will be vital for further developing the predictive models of nanoparticle fate and behaviour. These predictive models are needed to aid understanding of the risks that engineered nanoparticles pose to the environment and to provide an evidence base upon which to make decisions about management of nanoparticles in their post-production life cycles.

\section{References}

[1] B. Nowack, T.D. Bucheli, Environ. Pollut. 150 (2007) $5-22$.

[2] Y. Ju-Nam, J.R. Lead, Sci. Total Environ. 400 (2008) 396-414.

[3] H.P. Jarvie, S.M. King, Environ. Sci. Technol. 41 (2007) 2868-2873.

[4] H.P. Jarvie, H. Al-Obaidi, S.M. King, M.J. Bowes, M.J. Lawrence, A.F. Drake, M.A. Green, P.J. Dobson, Environ. Sci. Technol. 43 (2009) 8622-8628.

[5] P.J. Alvarez, V. Colvin, J. Lead, V. Stone, ACS Nano 3 (2009) $1616-1619$.

[6] H. Hyung, J.D. Fortner, J.B. Hughes, J.-H. Kim, Environ. Sci. Technol. 41 (2007) 179-184.

[7] Y. Zhang, Y. Chen, P. Westerhoff, J. Crittenden, Water Res. 43 (2009) 4249-4257. 


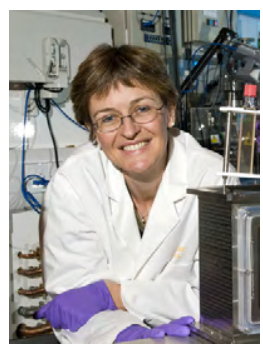

Dr Helen Jarvie is a Principal Scientist in Environmental Chemistry at the Centre for Ecology and Hydrology, Wallingford UK. Her research centres on the sources, transport and biogeochemical cycling of macronutrients (phosphorus and nitrogen) in watersheds, to promote sustainable management of surface freshwater resources. Her interests in colloidal phosphorus transport led to collaboration with Dr Stephen King on wider application of small-angle neutron scattering techniques to examine structure, interactions, behaviour and fate of natural aquatic and engineered nanoparticles in wastewater and surface waters. Helen has currently published 65 papers in international peer-reviewed journals.

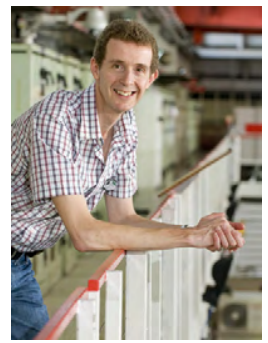

Dr Stephen King has a background in colloid science and is a Principal Scientist at the ISIS Pulsed Neutron Source, Harwell UK, where he has special responsibility for Environmental Science. He has published over 90 papers and contributed chapters for 4 text books. 